\title{
Lead(II) coordination polymers driven by pyridine-hydrazine donors: From anion-guided self-assembly to structural features
}

\author{
Ghodrat Mahmoudi, * Farhad Akbari Afkhami, Alan R. Kennedy, Fedor I. Zubkov, Ennio Zangrando, \\ Alexander M. Kirillov, ${ }_{f}$ Elies Molins, Mariusz P. Mitoraj, ${ }^{*}$ and Damir A. Safin*
}

\begin{abstract}
In this work we report extensive experimental and theoretical investigations on a new series of $\mathrm{Pb} \|$ coordination polymers exhibiting extended supramolecular architectures, namely $\left[\mathrm{Pb}_{2}(\mathrm{~L})(\mathrm{NCS})_{4}\right]_{n}(\mathbf{1}),\left[\left.\mathrm{Pb}(\mathrm{HLII})\right|_{2}\right]_{n}(\mathbf{2}),\left[\mathrm{Pb}\left(\mathrm{LIII}_{1}\right)\right]_{n}(\mathbf{3})$ and $\left[\mathrm{Pb}(\mathrm{HLiv})\left(\mathrm{NO}_{3}\right)_{2}\right]_{n} \cdot \mathrm{nMeOH}(4)$, which were self-assembled from different $\mathrm{Pb}$ ॥ salts and various pyridine-hydrazine based linkers, namely 1,2-bis(pyridin-3-ylmethylene)hydrazine (L)), (pyridin-4-ylmethylene)isonicotinohydrazide (HLII), 1-(pyridin2-yl)ethylidenenicotinohydrazide (HLIII) and phenyl(pyridin-2-yl)methylenenicotinohydrazide (HLiv), respectively. It is recognized, that the origin of self-assembling is fundamentally rooted in a dual donor $\left(6 \mathrm{~s}_{2} / 6 \mathrm{p}_{0}\right.$ hybridized lone electron pair) and electrophilic behaviour of $\mathrm{Pb}$ ॥. This allows to produce extended topologies from a 1D polymeric chain in 4 through a $2 \mathrm{D}$ layer in $\mathbf{2}$ to $3 \mathrm{D}$ frameworks in $\mathbf{1}$ and $\mathbf{3}$, predominantly due to cooperative action of both covalent and noncovalent tetrel interactions of overall type $\mathrm{Pb}-\mathrm{X}(\mathrm{X}=\mathrm{O}, \mathrm{N}, \mathrm{S}, \mathrm{I})$. Counterintuitively, the latter, seemingly weak interactions, have appeared to be even stronger than typical covalent bonds due to the presence of a bunch of supportive London

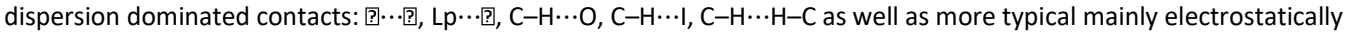
driven, $\mathrm{N}-\mathrm{H} \cdots \mathrm{O}$ or $\mathrm{N} / \mathrm{O}-\mathrm{H} \cdots \mathrm{O}$ hydrogen bonds. It is revealed, that the constituting generally strong tetrel type $\mathrm{Pb}-\mathrm{X}(\mathrm{X}=\mathrm{O}$, $\mathrm{N}, \mathrm{S}$, I) bonds, though dominated by a classic Coulomb term, are therefore characterized by a very important London dispersion constituent, extremely strong relativistic effects and the two ways dative-covalent $\mathrm{Pb} \leftrightarrow \mathrm{X}$ electrons charge delocalization contribution as revealed by the Extended Transition State Natural Orbital for Chemical Valence (ETS-NOCV) charge and energy decomposition scheme. It unravels that the pyridine-hydrazine linkers are also excellent London dispersion donors and, together with donor-acceptor properties of the heavy (relativistic) Pbıl atoms and nucleophilic counterions, lead to an extended self-assembling of 1-4.
\end{abstract}

Introduction Coordination polymers (CPs) are crystalline materials built by spontaneous self-assembly of building blocks including metal ions (nodes) and bridging ligands (linkers) where coordination bonds lead to the formation of infinite arrays of metal-ligand units that can extend into one, two or three dimensions.1-6 Given an increasing importance of CPs for their use in catalysis, luminescence and magnetic materials, $7-12$ the design and construction of these compounds and their structural investigation under the term of "Crystal Engineering» attract great attention and have become a hot topic.13 However, the ability to predict and control the supramolecular assembly of new molecules from complex reaction mixtures comprising several components still remains a challenge. Hence, more studies are required to understand the inter- and intramolecular forces that determine the patterns of molecular structures, crystal packing arrangements, topological features and properties of the resulting CPs.

Considering the coordination bonds as the primary and critical interactions to sustain a coordination network of metalligand arrays, other interactions such as hydrogen bonding and $\pi \cdots \pi$ stacking could play an important role in directing, extending and strengthening the metal-ligand framework.14-18 Coordination compounds of lead(II) gained a particular attraction since $\mathrm{Pb} \|$ is a heavy $\mathrm{p}$-block metal ion with a large ionic radius and a wide assortment of coordination numbers, which lead to unusual coordination geometries that are not exhibited, for example, by d-block transition metals.14,19-21 In particular, Pbı compounds with a variety of N/O/S/X-donor ligands $[X=$ (pseudo)halide] are usually hemidirected for coordination numbers up to five and holodirected when the coordination number is six and higher. These features are addressed by the stereochemically active 6 s2 lone-pair in the coordination sphere of $\mathrm{Pb}$ ॥ complexes.22-25 The tetrel bond in $\mathrm{Pb} \| \mathrm{CPs}$ is a consolidated and robust interaction, which can be 
used as an important tool in crystal engineering and supramolecular chemistry, namely in determining the crystal packing patterns and topological features of these compounds.26-34 The coordination chemistry of Pb॥l derivatives has also attracted an interest of physical chemists, reporting the prospects for the $207 \mathrm{~Pb}$ solid state NMR studies of lead(II) tetrel bonds. 35 Thus, the selection of organic linkers and counterions is also pivotal in order to give rise to lead-derived coordination networks with particular supramolecular interactions. 30 In continuation of our research, herein we describe the design, construction and structural investigation of new $\mathrm{Pb}$ ॥ coordination polymers, namely $\left[\mathrm{Pb}_{2}(\mathrm{LI})(\mathrm{NCS})_{4}\right]_{n}(\mathbf{1}),\left[\mathrm{Pb}(\mathrm{HL} ı) I_{2}\right] n$ (2), $[\mathrm{Pb}(\mathrm{LIII}) I]_{n}(3)$ and $\left[\mathrm{Pb}(\mathrm{HLIV})\left(\mathrm{NO}_{3}\right)_{2}\right]_{n} \cdot \mathrm{nMeOH}(4)$, which were obtained by self-assembly from different $\mathrm{Pb}$ ॥ salts and various closely related pyridine-hydrazine ligands, namely 1,2bis(pyridin-3-ylmethylene)hydrazine (LI), (pyridin-4ylmethylene)isonicotino-hydrazide (HLII), 1-(pyridin-2yl)ethylidenenicotinohydrazide (HLII) and phenyl(pyridin-2yl)methylenenicotinohydrazide (HLIv), respectively (Chart 1).

Chart 1 Diagram of the employed ligands.

These pyridine-hydrazine based ligands can chelate and/or bridge metal centers through their pyridyl nitrogen atoms, while the amide sites can participate in hydrogen bonding, thus being of ultimate importance to strengthen supramolecular arrays.30,36-41

In the present work, we also analyse the influence of counterions on the stereochemistry of prepared CPs, the structures of which are markedly controlled by the position of nitrogen donor in the pyridine rings. Various weak interactions like tetrel bonding, along with hydrogen bonding and $\pi \cdots \pi$ stacking have been detected in 1-4, confirming their important contribution to stabilize the framework structures of these compounds. By combining the Extended Transition State (ETS) method with the Natural Orbitals for Chemical Valence (NOCV), 42 a particular attention has been also drawn towards London dispersion forces and relativistic effects. These forces have not been widely investigated and recognized in heavy metal-containing polymeric structures but they appear to influence the behaviour of several compounds and often have a defining structure-guiding role.43,44 Although an exploration of functional properties of 1-4 has been out of the scope of the present study, such compounds may potentially show interesting photoluminescent, sensing, electrochemical or energy storage properties that can open up their diverse applications typical for Pbı metal-organic networks.45-47

\section{Results and discussion}

A one-pot reaction of equimolar amounts of $\mathrm{PbX}_{2}(\mathrm{X}=\mathrm{NCS}, \mathrm{I}$, $\mathrm{NO}_{3}$ ) and a series of closely related bis-pyridyl organic ligands LI and HLII-IV, in a branched tube apparatus in $\mathrm{MeOH}$ at $60^{\circ} \mathrm{C}$, leads to heteroleptic coordination polymers 1-4 (Scheme 1). These pyridine-hydrazine ligand species are ideal candidates to coordinate $\mathrm{Pb}$ II and to favour the formation of hemidirectional coordination compounds with an open face available for noncovalent bonding. Notably, the structure of $\mathbf{3}$ comprises the deprotonated form of the corresponding organic ligand, while in the other compounds the organic linker is in its neutral form. All compounds have been isolated as crystalline airstable 
solids in good yields, testifying the reported compositions as main final products, which were characterized by elemental analysis, FTIR spectroscopy and single-crystal Xray diffraction.

Scheme 1 Synthesis of 1-4 (tetrel bonds are shown as dashed lines).

Compound 1 crystallizes in triclinic space group $P-1$ and its asymmetric unit consists of one Pb॥ atom, half Lı moiety and two thiocyanate ligands. The structure shows centrosymmetric dinuclear lead entities where the metal centers are bridged by two nitrogen atoms of symmetry related $\mu$-NCS- anions and are separated by $4.4706(5) \AA$. Each metal center exhibits a tetracoordinate seesaw coordination geometry, being surrounded by the pyridyl nitrogen of the bridging $\mu$-Lı ligand and three nitrogen atoms from the thiocyanate anions (Fig. 1). The $\mathrm{Pb}-\mathrm{N}$ bond distances vary from $2.583(6)$ to $2.812(7) \AA$ (Table 1). A close inspection of the coordination sphere of Pb॥ in the structure of 1 revealed a hemidirected coordination geometry around the metal center with a pronounced gap. This facilitates closer approach of additional four thiocyanate sulfur atoms with the formation of corresponding tetrel bonds with $\mathrm{Pb}-\mathrm{S}$ distances ranging from 3.121(2) to 3.403(2) $\AA$ (Fg. 1, Table 1). This gives rise to a 3D supramolecular architecture with eight-coordinated $\mathrm{Pb}$ ॥ atoms.

Fig. 1 (top) Crystal structure of $\mathbf{1}$ (hydrogen atoms are omitted for clarity color code: $\mathrm{C}=$ gold, $\mathrm{N}=$ blue, $\mathrm{S}=$ yellow, $\mathrm{Pb}=$ magenta). (bottom) $\mathrm{A}$ simplified 3D network of 1 with the trinodal 3,4,8-connected net topology and point symbol of $\left(4_{13} \cdot 614 \cdot 8\right)\left(4_{3}\right)\left(4_{5} \cdot 6\right)$ (color code: $L_{1}=$ blue, NCS $=$ green, $\mathrm{Pb}=$ magenta)

Table 1 Covalent and tetrel bond lengths ( $\AA$ ) in the structures of 1-4. Complex Bond Bond donor Bond length Bond type $1 \mathrm{~Pb}-\mathrm{N} \mathrm{LI} 2.583(6)$ Covalent

NCS-2.602(7) Covalent

NCS-2.617(7) Covalent NCS-2.812(7) Covalent $\mathrm{Pb}-\mathrm{S}$ NCS-3.121(2) Tetrel NCS-3.198(2) Tetre

NCS-3.304(2) Tetrel NCS-3.403(2) Tetrel

$2 \mathrm{~Pb}-\mathrm{N} \mathrm{HL}$ 2.686(13) Covalent

HLı2.716(15) Covalent

Pb-I I-3.1547(16) Covalent

I-3.1960(16) Covalent

I-3.2301(16) Covalent

I-3.2686(16) Covalent

$3 \mathrm{~Pb}-\mathrm{N}$ HLII1 2.524(4) Covalent

HLIII 2.708(4) Covalent

HLIII 2.811(4) Covalent

$\mathrm{Pb}-\mathrm{O}$ HLIII 2.359(3) Covalent

Pb-I I-3.0070(4) Covalent

I-3.7731(5) Tetrel

I-3.9358(4) Tetrel

$4 \mathrm{~Pb}-\mathrm{N}$ HLiv 2.563(6) Covalent

HLiv 2.674(5) Covalent

HLIv 2.882(6) Covalent

$\mathrm{Pb}-\mathrm{O}$ HLiv 2.574(4) Covalent

$\mathrm{NO}$

-2.535(5) Covalent

2.665(5) Covalent

2.736(4) Covalent

2.894(5) Covalent

3.132(6) Tetre

3.349(6) Tetrel

The 3D framework of 1 was simplified, using the ToposPro 
software,48 resulting in a complex trinodal 3,4,8-connected threeperiodic topology defined by the point symbol of $(413 \cdot 614 \cdot 8)(43)(45 \cdot 6)$, where the $2 \mathrm{D}\left[\mathrm{Pb}(\mathrm{SCN})_{2}\right]_{n}$ corrugated sheets are interconnected by the $\mu$-Lı linkers. (Fig. 1). Notably, the overall structure of $\mathbf{1}$ is similar to that of complex $\left[\mathrm{Pb}_{2}\left(\mathrm{~L}_{1}\right) \mathrm{Cl}_{4}\right]_{n}$, which was fabricated from the same organic ligand $\mathrm{L}_{1}$ but using $\mathrm{PbCl}_{2}$ instead of $\mathrm{Pb}$ (NCS)2.30 This finding strongly supports the pseudohalide behavior of the thiocyanate anion in the structure of 1.

The structural analysis of $\mathbf{2}$ reveals a 2D layered coordination polymer network built by $\left[\mathrm{Pbl}_{2}\right]_{n}$ chain motifs interconnected by $\mu$-HLı linkers (Fig. 2). The compound crystallizes in triclinic space group $P-1$ and its asymmetric unit is composed of a Pbı center, one $\mu$-HLı organic ligand and two $\mu$-iodo ligands. The Pbı ion exhibits a slightly distorted octahedral geometry with a $\mathrm{PbN}_{2} \mathrm{l}_{4}$ chromophore. The coordination environment of the metal atom is formed by four $\mu$-I ligands and two N-donor atoms from two $\mu$-HLıl linkers, yielding a holodirected coordination sphere (Fig. 2). The Pb-I bond distances are in the range from 3.1547(16) to $3.2686(16)$ $\AA$, while the $\mathrm{Pb}-\mathrm{N}$ bonds are of $2.686(13)$ and $2.716(15) \AA$ (Table 1). Interestingly, the $\mathrm{Pb} \cdots \mathrm{Pb}$ separation between adjacent metal centers interconnected by the organic ligand attains $16.636(4) \AA$ that is the size of the $c$ axis, while the separation between two metal centers linked by two $\mu-1$ ligands is 4.6530(17) $\AA$, being equal to the length of the $a$ axis. The 2D metal-organic network in $\mathbf{2}$ is reinforced by the $\mathrm{N}-\mathrm{H} \cdots \mathrm{O}$ hydrogen bonds between the $\mathrm{NH}$ hydrogen atoms of the hydrazine moiety and the adjacent carbonyl oxygen atoms (Fig. 2, Table 2).

Fig. 2 (top) Crystal structure of $\mathbf{2}$ (hydrogen atoms except $\mathrm{NH}$ are omitted for clarity; color code: $\mathrm{C}=$ gold, $\mathrm{N}=$ blue, $\mathrm{O}=$ red, $\mathrm{I}=$ green, $\mathrm{Pb}=$ magenta; $\mathrm{NH} \cdots$ O hydrogen bond = cyan dashed line). (bottom) A simplified network of 2 with the uninodal 4-connected sql (Shubnikov tetragonal plane net) topology defined by the point symbol of $\left(4_{4} \cdot 6_{2}\right)$ (color code: $H L_{\|}=$blue, I = green, $\mathrm{Pb}=$ magenta).

Table 2 Hydrogen bond lengths $(\AA)$ and angles $\left({ }^{\circ}\right)$ for 2 and 4.

$\mathrm{D}-\mathrm{H} \cdots \mathrm{A} d(\mathrm{D}-\mathrm{H}) d(\mathrm{H} \cdots \mathrm{A}) d(\mathrm{D} \cdots \mathrm{A})$ ? (DHA)

$2 \mathrm{~N}-\mathrm{H} \cdots \mathrm{O} 0.862 .142 .818(17) 135$

$4 \mathrm{~N}-\mathrm{H} \cdots \mathrm{O} 0.83(6) 2.14(6) 2.860(7) 144(5)$

$\mathrm{O}-\mathrm{H} \cdots \mathrm{O} 0.842 .032 .841(8) 162$

From a topological perspective, the 2D metal-organic layer in $\mathbf{2}$ is assembled from the 4-connected Pbı nodes and 2connected $\mathbf{H L}$ II and I linkers. This layer can be classified as a uninodal 4-connected sql (Shubnikov tetragonal plane net) with the point symbol (44.62) (Fig. 2). A comparable structural topology was reported for related derivatives containing bis(pyridin-4-ylmethylene)hydrazine or 4,4'-bipy.49,50

Fig. $\mathbf{3}$ (top) Crystal structure of $\mathbf{3}$ (hydrogen atoms are omitted for clarity; color code: $\mathrm{C}=$ gold, $\mathrm{N}=$ blue, $\mathrm{O}=$ red $\mathrm{I}$ = green, $\mathrm{Pb}=$ magenta; $\mathrm{Pb}-\mathrm{I}$ tetrel bond = cyan dashed line). (bottom) A simplified network of $\mathbf{3}$ with the binodal 3,5-connected net topology defined by the point symbol of $(42 \cdot 65 \cdot 83)(42 \cdot 6)$ (color code: LIII $_{2}$ blue, I = green, $\mathrm{Pb}=$ magenta).

Complex 3 crystallizes in monoclinic space group $P 21 / n$ and its asymmetric unit comprises one Pbı atom, one $\mu$-Lı! ligand and one iodide ligand. The metal center is covalently pentacoordinated featuring a $\mathrm{N}_{3} \mathrm{Ol}$ coordination environment, which is filled by the $\mathrm{N}_{2} \mathrm{O}$-donor set from the deprotonated $\mu$-LIII, a 4pyridyl nitrogen donor from a symmetry related organic moiety and an iodide ligand (Fig. 3). As a result, an infinite zigzag 
1D metal-organic chain is generated along the [101] crystallographic direction (Fig. 3). The $\mathrm{Pb}-\mathrm{O}$ and $\mathrm{Pb}-\mathrm{N}$ bond chelating distances are 2.359(3), 2.525(4), and 2.708(4) $\AA$, respectively, while the $\mathrm{Pb}-\mathrm{N}$ (pyridine) bond length is considerably longer, 2.811(4) $\AA$ (Table 1 ). The $\mathrm{Pb}-\mathrm{I}$ bond length of 3.0070(4) $\AA$ is in the normal range as previously observed for a terminal iodide.28 The metal center in $\mathbf{3}$ exhibits a hemidirected coordination sphere and this allows the adjacent 1D metal-organic chains to held together via additional Pbtetrel bonds of 3.7731(5) and 3.9358(4) A. Despite being rather long, these $\mathrm{Pb}-\mathrm{I}$ contacts are still below the sum of Van der Waals radii for $\mathrm{Pb}(2.02 \AA)$ and I ( $1.98 \AA$ ) atoms. The resulting 3D supramolecular framework (Fig. 3 ) can be topologically described as a binodal 3,5-connected net defined by the point symbol of $(42.65 \cdot 83)(42 \cdot 6)$. It is to note that in the compound obtained with a ligand similar to LiII, but having a phenyl group replacing the methyl, the polymeric arrangement is not formed and the corresponding $\mathrm{Pb}-\mathrm{N}$ bond distance is of about $3.25 \AA$. The difference can be explained by a tetrel bonding beside a concurrent agostic interaction with the hydrogen atom in ortho position to the $\mathrm{N}$ (pyridine) atom.51 Compound $\mathbf{4}$ crystallizes in triclinic space group $P-1$ and its asymmetric unit comprises one Pbı, one $\mu$-HLıv organic ligand, one $\mu$-bridging and one terminal nitrate ligands as well as one lattice methanol molecule. The metal atom is coordinated by the tridentate $\mathrm{HLIv}$ ligand through the $\mathrm{N}_{2} \mathrm{O}$ chelate moiety and, in addition, is bound by the terminal 3-pyridyl nitrogen atom of a symmetry related HLiv fragment to form a dinuclear $[\mathrm{Pb}(\mathrm{HLIV})]_{2}$ entity (Fig. 4). The $\mathrm{Pb}-\mathrm{N}$ bond lengths vary from $2.562(5)$ to $2.882(6) \AA$ with the longest distance corresponding to coordination with the 3-pyridyl nitrogen (Table 2). The coordination sphere of the $\mathrm{Pb}$ ॥l atom is completed by two oxygen atoms from the terminal $\mu$-nitrate and by two oxygen atoms from the bridging $\mu$-nitrate ligands that form a zig-zag 1D metal-organic chain (Fig. 4). The $\mathrm{Pb}-\mathrm{O}$ (nitrate) distances fall in the range of 2.536(4)-2.894(5) $\AA$ (Table 1). Notably, although the coordination environment of $\mathrm{Pb}$ ॥l atom in the structure of $\mathbf{4}$ is formed by eight covalently linked donor atoms, yielding a $\mathrm{PbN}_{3} \mathrm{O}_{5}$ chromophore, there is still enough room to link two additional oxygen atoms from the bridging nitrate ligands with formation of tetrel bonds (Fig. 4, Table 1). Within the 1D chain, the metal centers are separated by about $5.79 \AA$ via the bridging nitrate moieties and by about $7.97 \AA$ between the dinuclear $[\mathrm{Pb} \text { (HLIV) }]_{2}$ entities. From the topological perspective, the 1D chain in $\mathbf{4}$ can be classified as a decorated uninodal 2-connected 2C1 chain (Fig. 4).

The crystal packing of $\mathbf{4}$ also shows that the 1D metalorganic chains are interconnected through the $\mathrm{N}-\mathrm{H} \cdots \mathrm{O}$

hydrogen bonds between the $\mathrm{NH}$ site and the oxygen atom of a symmetry related nitrate from an adjacent chain (Table 2 ). This network is comparable with that found in the structure of a similar complex constructed from $\mathrm{Pb}\left(\mathrm{NO}_{3}\right)_{2}$ and a related ligand differing from HLiv having a methyl replacing the phenyl group.52 The lattice methanol molecule is appended to one of the coordinated oxygen atoms of the bridging nitrate ligand through $\mathrm{O}-\mathrm{H} \cdots \mathrm{O}$ hydrogen bonding (Table 2 ).

Fig. 4 (top) Crystal structure of $\mathbf{4}$ (hydrogen atoms except $\mathrm{NH}$ and solvent molecules are omitted for clarity; color code: $\mathrm{C}=$ gold, $\mathrm{N}=$ blue, $\mathrm{O}=$ red, $\mathrm{Pb}$ = magenta; $\mathrm{Pb}-\mathrm{O}$ tetrel bond = cyan dashed line). (bottom) A simplified network of $\mathbf{4}$ with the uninodal 2-connected $2 \mathrm{C} 1$ topology (color code: HLiv = blue, $\mathrm{NO}_{3}=$ green, $\mathrm{Pb}=$ magenta). 
by $\pi \cdots \pi$ stacking interactions formed between the pyridyl fragments (Table 3 ). The same interactions are hardly present in $\mathbf{2}$ due to too long distances ( $>4 \AA$ ) between pirydyl fragments.

In order to provide further insight into the nature of the constituting covalent and non-covalent connections in $\mathbf{1 - 4}$, we have made use of the charge and energy decomposition scheme ETS-NOCV, 42 as implemented in the ADF53-55 suite of programs. We have applied the BLYP-D3/TZP protocol since such type of computational details has proven to provide reliable data for non-covalent interactions. 56 Let us start with the electronic structure analysis of the cluster model $[\mathrm{Pb}(\mathrm{L}$ III) $)] 2$, extracted from 3. Molecular electrostatic potential contour clearly demonstrates the existence of the electrophilic bay in the vicinity of the lead atoms, what well rationalizes the formation of various $\mathrm{Pb}-\mathrm{X}$ interactions, $\mathrm{X}=$ electron donors (Fig. 5). The ETS-NOCV based gathered data show significant strength of the tetrel $\mathrm{Pb}-\mathrm{I}$ bond as indicated by the calculated interaction energy $\Delta E_{\text {total }}=-46.96 \mathrm{kcal} / \mathrm{mol}$ (Fig. 5). This is particularly interesting given the long $\mathrm{Pb}-\mathrm{I}$ distances of $\mathrm{ca}$. $3.773 \AA$.

Table $3 \pi \cdots \pi$ ring interactions distances $(\AA)$ and angles $\left({ }^{\circ}\right)$ for complexes $\mathbf{1}, \mathbf{3}$ and $\mathbf{4} . a$ $\mathrm{Cg}(/) \mathrm{Cg}(J) d[\mathrm{Cg}(/)-\mathrm{Cg}(J)] \alpha \beta \gamma$ slippage

1 3-Py 3-Py 3.882(5) 0.0(4) 27.627 .61 .796

3 2-Py 4-Py 4.065(3) 19.9(2) 37.318 .8 -

4 2-Py 3-Py 3.668(4) 14.4(3) $10.49 .6-$

2-Py 2-Py 3.826(4) 0.0(3) 26.226 .21 .690

${ }_{a} \mathrm{Cg}(I)-\mathrm{Cg}(J)$ : distance between ring centroids; $\alpha$ : dihedral angle between planes $\mathrm{Cg}(/)$ and $\mathrm{Cg}(J) ; \beta$ : angle $\mathrm{Cg}(/) \rightarrow \mathrm{Cg}(J)$ vector and normal to plane I; $\gamma$ :

angle $\mathrm{Cg}(/) \rightarrow \mathrm{Cg}(J)$ vector and normal to plane $J$; slippage: distance between $\mathrm{Cg}(I)$ and perpendicular projection of $\mathrm{Cg}(J)$ on ring $/$.

Fig. 5 (top) Molecular electrostatic potential for the crystal synthon in $\mathbf{3}$.

(middle) The ETS-NOCV based results describing tetrel $\mathrm{Pb}-\mathrm{I}$ and covalent $\mathrm{Pb}$ -

$\mathrm{N}$ bonds and (bottom), the overall deformation density $\Delta$ ?orb with the

corresponding $\Delta E_{\text {orb }}$ for the $\mathrm{Pb}-\mathrm{I}$ and $\mathrm{Pb}-\mathrm{N}$ bonds.

Although the electrostatic origin of such interactions is

evident by the prevailing $\Delta E_{\text {elstat }}=-36.65 \mathrm{kcal} / \mathrm{mol}$ ( $41 \%$ of the overall stabilization), the London dispersion constituent,

$\Delta E_{\text {dispersion }}=-33.20 \mathrm{kcal} / \mathrm{mol}$, is of comparable importance

( $37 \%$ of the overall stabilization), followed by the least crucial charge delocalization contribution $\Delta E_{\text {orb }}=-20.00 \mathrm{kcal} / \mathrm{mol}$. It must be referenced that the electrostatic and charge delocalization terms are known as important constituents of tetrel bonds.57-61 We have noticed herein for the first time that London dispersion forces are crucial cofactors for the studied species and can reach comparable values in magnitude. The corresponding (to $\Delta E_{\text {orb}}$ ) deformation density $\Delta$ ?lorb demonstrates dative-covalent nature of the $\mathrm{Pb}-\mathrm{I}$ interactions as arising from both electron density transfers involving the lone electron pairs $(\mathrm{Lp}): \mathrm{Lp}(\mathrm{I}) \rightarrow \mathrm{O}^{*}(\mathrm{~Pb}-\mathrm{I})$ and $\mathrm{Lp}(\mathrm{Pb}, 4 \mathrm{~s} / 4 \mathrm{p}$ hybridized) $\rightarrow$ ? ? $^{*}(\mathrm{~Pb}-\mathrm{I})$ (Fig. 5). It is worth noting that the mentioned transfers are further augmented by the $\mathrm{C}-\mathrm{H} \cdots \mathrm{I}$ contacts (Fig. 5). It is important to stress, that the strength of a single tetrel $\mathrm{Pb}-\mathrm{I}$ bond, having $\Delta E_{\text {total }}=-23.5 \mathrm{kcal} / \mathrm{mol}$, is comparable to the strength of the formally covalent $\mathrm{Pb}-\mathrm{N}$ bond $(2.81 \AA$ ) $)$ with $\Delta E_{\text {total }}=-26.21 \mathrm{kcal} / \mathrm{mol}$ (Fig. 5).

Table 4 The influence of relativistic effects on the $\mathrm{Pb}-\mathrm{I}$ and $\mathrm{Pb}-\mathrm{N}$ bonds in the cluster models of $\mathbf{3}$. 
ZORA/scalar/TZP -49.96 $42.89-20.00-36.65-33.20$

Non-relativistic $-37.1952 .84-18.94-37.89-33.20$

ZORA/SO/TZP -66.17 $42.89-39.22-36.65-33.20$

$\mathrm{Pb}-\mathrm{N}$

ZORA/scalar/TZP -26.21 41.43-15.96-31.44 -20.25

Non-relativistic $-23.8447 .95-17.29-34.25-20.25$

ZORA/SO/TZP -45.43 $41.43-35.17$-31.44-20.25

$\Delta E_{\text {int }}=\Delta E_{\text {Pauli }}+\Delta E_{\text {orb }}+\Delta E_{\text {elstat }}+\Delta E_{\text {dispersion }}$

Furthermore, we have also unveiled the significance of relativistic effects in 3, accounted at both ZORA/scalar/TZP and ZORA/SO/TZP, for the amplification of the strength of both $\mathrm{Pb}-$ $\mathrm{I}$ and $\mathrm{Pb}-\mathrm{N}$ bonds mainly due to alleviation of the Pauli/kinetic constituent. Interestingly, accounting for spin-orbit effects at ZORA/SO/TZP for $\mathrm{Pb}-\mathrm{I}$ and $\mathrm{Pb}-\mathrm{N}$ bonds leads to their strengthening by $\sim 78 \%$ and $90 \%$ with respect to nonrelativistic computations, respectively (Table 4). Such intriguing effect is, in turn, rooted in amplification of the charge delocalization constituent. The relative role of London dispersion forces, electrostatic and charge delocalizations is also similar within formally non-covalent $\mathrm{Pb}-\mathrm{I}$ and covalent $\mathrm{Pb}-\mathrm{N}$ bonds (Fig. 5). Overall deformation density $\Delta$ ? corresponding to $\mathrm{Pb}-\mathrm{N}$ in $\mathbf{3}$, indicates that, apart from the typical dative-covalent features due to the two-ways charge transfers $\mathrm{Lp}(\mathrm{N}) \rightarrow \mathrm{O}^{*}(\mathrm{~Pb}-\mathrm{N} / \mathrm{O})$ and $\mathrm{Lp}\left(\mathrm{Pb}, 6 \mathrm{~s}_{2} / 6 \mathrm{p}_{0}\right.$ hybridized) $\rightarrow$ ? $*(\mathrm{~N}-\mathrm{C})$, one can notice additional charge delocalization caused by extra non-covalent interactions involving $\mathrm{C}-\mathrm{H}$ bonds: $\mathrm{C}-\mathrm{H} \cdots \mathrm{O}, \mathrm{C}-\mathrm{H} \cdots \mathrm{I}$ and $\mathrm{C}-\mathrm{H} \cdots \mathrm{H}-\mathrm{C}$. Notably, the same set of connections are also recovered by the topological QTAIM and $\mathrm{NCI}$ methods which are also widely applied for detection of chemical bonds (Fig. 6). Particularly, in the light of modern quantum chemistry methods, the latter ones are gaining increasing attention by investigators for a better understanding of steric crowding.43,44,62-64

Fig. 6 (top) QTAIM molecular graph and (bottom) the $\mathrm{NCl}$ contour for the crystal model of $\mathbf{3}$ (the same model as in Fig. 5).

Fig. 7 ETS-NOCV/BLYP-D3/TZP energy decomposition results for the crystal models of 1. (top) The considered model and ETS based results, and (bottom) the overall deformation density $\Delta$ ? orb with the corresponding $\Delta E_{\text {orb. }}$

The strength of the $\mathrm{Pb}-\mathrm{N}$ bond in models analogous to 1 and 2 has a $\Delta E_{\text {total }}$ of $-34.60 \mathrm{kcal} / \mathrm{mol}$ and $-22.47 \mathrm{kcal} / \mathrm{mol}$, respectively (Fig. 7 and 8 ). It is significant to point out that the electrostatically dominated $\mathrm{Pb}-\mathrm{O}$ tetrel bond in the cluster model of 4 , with calculated $\Delta E_{\text {total }}=-53.81 \mathrm{kcal} / \mathrm{mol}$, is far stronger with respect to the $\Delta E$ total values for $\mathrm{Pb}-\mathrm{N}$ bonds in 1 and 2 reported above $(-34.6$ and $-22.47 \mathrm{kcal} / \mathrm{mol}$ ) (Fig. 5, 7 and 8).

Fig. 8 ETS-NOCV/BLYP-D3/TZP energy decomposition results for the crystal models of 2. (top) The considered model and ETS based results, and (bottom) the overall deformation density $\Delta$ ? orb with the corresponding $\Delta E_{\text {orb. }}$

Notably, in addition to dominant dative-covalent charge transfers within $\mathrm{Pb}-\mathrm{O}$, extra electron delocalization due to $\mathrm{C}-$ $\mathrm{H} \cdots \mathrm{O}$ and $\mathrm{Lp}(\mathrm{O}) \cdots$ ? (Fig. 9) can be detected. In 4, methanol species is weakly bound to the $\mathrm{NO}_{3}$ unit $\left(\Delta E_{\text {total }}=-11.36\right.$ $\mathrm{kcal} / \mathrm{mol}$ ) through typical, electrostatically dominated hydrogen bonding $\mathrm{O}-\mathrm{H} \cdots \mathrm{O}$ (39\% of the overall stabilization); though, charge delocalization and London dispersion forces are also similarly crucial (Fig. 9). Furthermore, cooperative action of the $\mathrm{Pb}-\mathrm{S}$ with $\pi \cdots \pi$ stacking, which mostly constitutes 1 , leads to the more pronounced $\Delta E_{\text {total }}=-54.02 \mathrm{kcal} / \mathrm{mol}$ (Fig. 7). Finally, it is interesting to highlight, that pure $\mathrm{Pb}-\mathrm{I}$ bond in 
the model of $\mathbf{2}$ is extremely weak with $\Delta E_{\text {total }}=-2.45 \mathrm{kcal} / \mathrm{mol}$ but becomes stronger when cooperative action of $\mathrm{N}-\mathrm{H} \cdots \mathrm{O}$ and $\pi \cdots \pi$ is gradually taken into account, leading to amplification of the overall stabilization up to $\Delta E_{\text {total }}=-30.49 \mathrm{kcal} / \mathrm{mol}$ (Fig. 8).

Fig. 9 ETS-NOCV/BLYP-D3/TZP energy decomposition results for the crystal models of 4 . (top) The considered model and ETS based results, and (bottom) the overall deformation density $\Delta$ porb with the corresponding $\Delta E_{\text {orb. }}$.

\section{Conclusions}

In summary, we have designed and fully characterized four new $\mathrm{Pb}$ ॥l coordination polymers, $\left[\mathrm{Pb}_{2}\left(\mathrm{LI}_{1}\right)(\mathrm{NCS})_{4}\right]_{n}(\mathbf{1})$,

$\left[\mathrm{Pb}(\mathrm{HLII}) I_{2}\right]_{n}(\mathbf{2}),[\mathrm{Pb}(\mathrm{LIII})]_{n}(\mathbf{3})$ and $\left[\mathrm{Pb}(\mathrm{HLIV})\left(\mathrm{NO}_{3}\right)_{2}\right]_{n} \cdot \mathrm{nMeOH}(4)$, assembled from $\mathrm{PbX}_{2}$ salts $\left(\mathrm{X}=\mathrm{NCS}, \mathrm{I}, \mathrm{NO}_{3}\right)$ and four closelyrelated bis(pyridine)-hydrazine based linkers. These pyridinehydrazine building blocks act as linkers in which the pyridine nitrogen atoms have a predominant role in the construction of the polymeric structure. On the other hand, the ancillary inorganic ligands have an influence on the coordination geometry around the metal centers. These factors along with numerous tetrel bonds and other types of intermolecular interactions contribute to the reinforcement and extension of the metal-organic structures to give supramolecular networks of higher dimensionality.

According to the topological analysis, compound 1 discloses a trinodal 3,4,8-connected supramolecular 3D net. The structure of $\mathbf{2}$ features a uninodal 4-connected 2D metalorganic layer with a sql (Shubnikov tetragonal plane net) topology. The 3D supramolecular network of $\mathbf{3}$ is topologically described as a binodal 3,5-connected net, while the 1D network of $\mathbf{4}$ is rationalized as a uninodal $2 \mathrm{C} 1$ chain. Apart from structural and topological diversity, this work demonstrates the aptitude of $\mathrm{Pb}$ ॥I ions to exhibit different coordination numbers in these compounds, including an interesting hemidirected coordination in two cases. All these features arise from the cooperative action of various covalent and tetrel bonds of $\mathrm{Pb}-\mathrm{X}(\mathrm{X}=\mathrm{N}, \mathrm{I}, \mathrm{S}, \mathrm{O})$ type. It is unveiled that seemingly weak electrostatically dominated non-covalent tetrel bonds, with $\pi E_{\text {total }}(\mathrm{Pb}-\mathrm{I})=-30.49 \mathrm{kcal} / \mathrm{mol}$ in 2,

$\Delta E_{\text {total }}(\mathrm{Pb}-\mathrm{S})=-54.02 \mathrm{kcal} / \mathrm{mol}$ in 1 and $\Delta E_{\text {total }}(\mathrm{Pb}-\mathrm{O})=-53.81$ $\mathrm{kcal} / \mathrm{mol}$ in 4, can be even stronger than formally considered covalent $\mathrm{Pb}-\mathrm{N}$ connections with interaction $\Delta E$ total energy of $22.47 \mathrm{kcal} / \mathrm{mol}$ in $\mathbf{2}$ and $-34.6 \mathrm{kcal} / \mathrm{mol}$ in 1 . The former connections are supported by a set of weak London dispersion dominated contacts stemming from $\pi \cdots \pi, \mathrm{Lp}(\mathrm{O}) \cdots$ ?], $\mathrm{C}-\mathrm{H} \cdots \mathrm{O}$, $\mathrm{C}-\mathrm{H} \cdots \mathrm{I}$, and $\mathrm{C}-\mathrm{H} \cdots \mathrm{H}-\mathrm{C}$ interactions as well by more typical, essentially electrostatically driven, $\mathrm{N}-\mathrm{H} \cdots \mathrm{O}$ or $\mathrm{O}-\mathrm{H} \cdots \mathrm{O}$ hydrogen bonds.65-72 Finally, all $\mathrm{Pb}-\mathrm{X}$ bonds exhibiting dativecovalent features in 1-4, though dominated by classical Coulomb forces, contain also important London dispersion constituent. Notably, the $\Delta$ ? lorb-based picture of chemical bonding is expectedly qualitatively similar to the QTAIM and $\mathrm{NCl}$ based interpretations. Our outcomes on topological features of tetrel bonds are in line with the recent literature.7377

We have also revealed the great importance of relativistic effects for the strengthening of $\mathrm{Pb}-\mathrm{X}$ bonds (up to 90\%) due to alleviation of the Pauli/kinetic constituent and amplification of charge delocalization term.

Finally, this study contributes to widening the family of $\mathrm{Pb}_{\text {॥I }}$ CPs constructed from multifunctional pyridine-hydrazine donor ligands and highlights, on the basis of in-depth 
structural and topological analysis as well as theoretical methods, the importance of different types of non-covalent interactions that, in some cases, can be energetically compared to covalent bonds. The explored herein ligand systems can also be potentially applied for the design of extended architectures that involve other Group 14 elements (e.g. Sn, Ge) capable of forming tetrel bonds. 22,33 We believe that the findings of the present study might be of particular importance for synthetic chemists when selecting an appropriate set of principal and auxiliary ligands while designing new lead(II) metal-organic architectures.

\section{Experimental}

\section{Physical measurements}

Microanalyses were performed using a Heraeus CHN-O-Rapid analyzer. The FTIR spectra were recorded on a Bruker Tensor 27 FTIR spectrometer.

\section{Synthesis}

Complexes were synthesized using a branched tube method. 34 A mixture of LI or HLII-IV $(0.105,0.113,0.120$ and $0.151 \mathrm{~g}$, respectively; $0.5 \mathrm{mmol}$ ) and $\mathrm{PbNCS} 2, \mathrm{Pbl} 2$ or $\mathrm{Pb}\left(\mathrm{NO}_{3}\right)_{2}(0.162$, 0.231 and $0.166 \mathrm{~g}$, respectively; $0.5 \mathrm{mmol}$ ) was placed into the main arm of a branched tube. $\mathrm{MeOH}(15 \mathrm{~mL})$ was carefully added to fill the arms. The tube was sealed and immersed in an oil bath at $60^{\circ} \mathrm{C}$ while the branched arm was kept at ambient temperature. After about one week, X-ray suitable single crystals of 1-4 were formed in the cooler arm of the tube. Crystals were isolated by filtration.

$\left[\mathrm{Pb}_{2}\left(\mathrm{LL}_{1}\right)(\mathrm{NCS})_{4}\right]_{n}$ (1). Yellow block-like crystals. Yield: $0.116 \mathrm{~g}$ (54\%). FTIR, v: 1622 (C=N), 2014 (NCS), 2925 (CH) cm-1. Anal. Calc. for $\mathrm{C}_{16} \mathrm{H}_{10} \mathrm{~N}_{8} \mathrm{~Pb}_{2} \mathrm{~S}_{4}$ (856.95): C 22.43, H 1.18 and $\mathrm{N} 13.08$; found: C 22.30, H 1.26 and N 13.18\%.

$\left[\mathrm{Pb}(\mathrm{HLII}) \mathrm{I}_{2}\right]_{n}$ (2). Orange prism-like crystals. Yield: $0.292 \mathrm{~g}$ (85\%). FTIR, v: $1605(\mathrm{C}=\mathrm{N}), 1674(\mathrm{C}=\mathrm{O}), 2855(\mathrm{CH}) \mathrm{cm}-1$. Anal. Calc. for $\mathrm{C}_{12} \mathrm{H}_{10} \mathrm{l}_{2} \mathrm{~N} 4 \mathrm{OPb}$ (687.25): C 20.97, H 1.47 and $\mathrm{N}$ 8.15; found: C 20.61, H 1.58 and N 8.32\%.

$[\mathrm{Pb}(\mathrm{LIII})]_{n}(3)$. Yellow-orange plate-like crystals. Yield: $0.198 \mathrm{~g}$ (69\%). FTIR, v: 1589 (C=N), $1675(\mathrm{C}=0), 2956(\mathrm{CH}) \mathrm{cm}-1$. Anal. Calc. for $\mathrm{C}_{13} \mathrm{H}_{11} \mathrm{IN} \mathrm{N}_{4} \mathrm{OPb}$ (573.36): C 27.23, H 1.93 and N 9.77;

found: $\mathrm{C} 27.32, \mathrm{H} 1.73$ and $\mathrm{N} 9.58 \%$.

$\left[\mathrm{Pb}(\mathrm{HLiv})\left(\mathrm{NO}_{3}\right)_{2}\right]_{n} \cdot \mathrm{nMeOH}(4)$. Yellow prism-like crystals. Yield: $0.290 \mathrm{~g}(87 \%)$. FTIR, v: 1357 (NO3), $1594(\mathrm{C}=\mathrm{N}), 1763$ (C=O), $2943(\mathrm{CH}), 3258(\mathrm{OH}) \mathrm{cm}-1$. Anal. Calc. for $\mathrm{C}_{19} \mathrm{H}_{18} \mathrm{~N}_{6} \mathrm{O} 8 \mathrm{~Pb}$ (665.59): C 34.29, H 2.73 and N 12.63; found: C 34.41, H 2.85 and $\mathrm{N} 12.87 \%$.

\section{ETS-NOCV charge and energy decomposition}

The Natural Orbitals for Chemical Valence (NOCV)

iconstitute

the canonical representation for a differential density matrix $\Delta P$. It is formed by subtracting the appropriate orthogonalized molecular fragments density matrices from a density matrix of a molecule under consideration, in which $\Delta P$ adopts a diagonal form. It gives rise to the corresponding eigenvalues $v_{i}$ and the related vectors

i. NOCVs occur in pairs $\left(\psi-k, \psi_{k}\right)$ related to

$\left|v_{k}\right|$ and they decompose overall deformation density $\Delta \rho$ orb into bonding components with different symmetries $(\Delta \rho k) .54$ Usually, a few $k$ allow to recover a major shape of $\Delta \rho$. By combining NOCVs with ETS scheme in ETS-NOCV,42 one can 
obtain the related energetics, $\Delta E_{\text {orb }}(k)$, in addition to qualitative picture emerging from $\Delta \rho k$. ETS originally divides the total bonding energy between fragments, $\Delta E$ total, into four distinct components: $\Delta E_{\text {total }}=\Delta E_{\text {elstat }}+\Delta E_{\text {pauli }}+\Delta E_{\text {orb }}+$

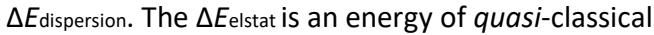
electrostatic interaction between fragments. The next term, $\Delta E$ Pauli, is responsible for the repulsive Pauli interaction between occupied orbitals on the two fragments. The third component, $\Delta E_{\text {orb }}$, is stabilizing and shows formation of a chemical bond, including polarizations. In the ETS-NOCV 42,54 scheme $\Delta E_{\text {orb }}$ is further decomposed into contributions $\Delta E_{\text {orb }}(k)$ corresponding to $\Delta \rho$ k.54 Finally, $\Delta E_{\text {dispersion denotes the }}$ semiempirical Grimme dispersion correction (D3). We have applied the BLYP-D3/TZP since such type of computational details haave proven to provide reliable data for non-covalent interactions.56

\section{Single-crystal X-ray diffraction}

Diffraction data were collected on a Bruker APEX-II CCD, an Oxford Diffraction Xcalibur E, or an Enraf Nonius FR590 diffractometers with graphite-monochromated Mo-K $\alpha$ radiation $(\lambda=0.71073 \AA)$. Data reduction was performed with the Bruker APEX2, SAINT, 78 CrysAlisPro79 and XCAD480 programs. Empirical absorption corrections were applied to all datasets. All the structures were solved by direct methods 81 and refined by full matrix least-squares procedures using SHELXTL.82 All non-hydrogen atoms were refined with anisotropic displacement parameters and the contribution of hydrogen atoms placed at calculated positions was included in the final cycles of refinement.

Crystal data for $1 . \mathrm{C}_{8} \mathrm{H}_{5} \mathrm{~N}_{4} \mathrm{PbS}_{2}, \mathrm{Mr}_{\mathrm{r}}=428.48 \mathrm{~g} \mathrm{~mol}-1, T=293(2)$ $\mathrm{K}$, triclinic, space group $P-1, a=6.7965(5), b=7.1870(6), c=$ 11.8200(9) $\AA, \alpha=75.460(1), b=82.148(1), \gamma=77.434(1)^{\circ}, V=$ $543.43(7) \AA_{3}, Z=2, \rho=2.619 \mathrm{~g} \mathrm{~cm}-3, \mu(\mathrm{Mo}-\mathrm{K \alpha} \alpha)=15.876 \mathrm{~mm}-1$, reflections: 5450 collected, 2662 unique, $R$ int $=0.035, R_{1}($ all $)=$ $0.0352, w R_{2}$ (all) $=0.0928, S=1.104$.

Crystal data for 2. $\mathrm{C}_{12} \mathrm{H}_{10} \mathrm{l}_{2} \mathrm{~N}_{4} \mathrm{OPb}, \mathrm{Mr}_{\mathrm{r}}=687.23 \mathrm{~g} \mathrm{~mol}-1, T=$ 293(2) K, triclinic, space group $P-1, a=4.6530(15), b=$ 11.365(2), $c=16.636(4) \AA, \alpha=70.590(18), b=88.62(2), \gamma=$ $86.101(19)^{\circ}, V=827.8(4) \AA_{3}, Z=2, \rho=2.757 \mathrm{~g} \mathrm{~cm}-3, \mu$ (Mo-K $\left.\alpha\right)$ $=13.920 \mathrm{~mm}-1$, reflections: 3581 collected, 3581 unique, $R_{1}($ all $)=0.1093, w R_{2}$ (all) $=0.1509, S=1.037$.

Crystal data for 3. $\mathrm{C}_{13} \mathrm{H}_{11} \mathrm{IN}_{4} \mathrm{OPb}, \mathrm{Mr}_{\mathrm{r}}=573.75 \mathrm{~g} \mathrm{~mol}-1, T=$ $150(2) \mathrm{K}$, monoclinic, space group $P 21 / n, a=6.8225(2), b=$ $18.6186(5), c=11.9818(3) \AA$, $b=104.108(3)^{\circ}, V=1476.09$ (7) $\AA_{3}, Z=4, \rho=2.580 \mathrm{~g} \mathrm{~cm}-3, \mu(\mathrm{Mo}-\mathrm{K} \alpha)=13.522 \mathrm{~mm}-1$, reflections: 8732 collected, 3549 unique, $R$ int $=0.037, R_{1}($ all $)=$ $0.0384, w R_{2}$ (all) $=0.0526, S=1.029$.

Crystal data 4. $\mathrm{C}_{18} \mathrm{H}_{15} \mathrm{~N}_{6} \mathrm{O}_{7} \mathrm{~Pb}, \mathrm{CH}_{4} \mathrm{O} ; \mathrm{Mr}_{\mathrm{r}}=665.58 \mathrm{~g} \mathrm{~mol}-1, T=$ $193(2) \mathrm{K}$, triclinic, space group $P-1, a=9.1144(18), b=$ 11.331(2), $c=12.168(2) \AA, \alpha=81.869(3), b=74.622(4), \gamma=$ $71.200(3)^{\circ}, V=1144.9(4) \AA_{3}, Z=2, \rho=1.931 \mathrm{~g} \mathrm{~cm}-3, \mu$ (Mo-K $\left.\alpha\right)$ $=7.426 \mathrm{~mm}-1$, reflections: 6161 collected, 3980 unique, $R$ int $=$ $0.024, R_{1}($ all $)=0.0355, w R_{2}($ all $)=0.0785, S=1.077$.

\section{Acknowledgements}

We are grateful to the University of Maragheh for the financial support of this research. The publication has been prepared with the support of the "RUDN University Program 5-100" (recipient F. I. Zubkov, synthesis of the ligands). DFT calculations were partially performed using the PL-Grid 
Infrastructure and resources provided by the ACC Cyfronet AGH (Cracow, Poland). A.V.G acknowledges the FCT and Instituto Superior Técnico (DL 57/2016 and L 57/ 2017 Program, Contract no: IST-ID/110/2018). A. M. Kirillov acknowledges the FCT and Portugal 2020 (LISBOA-01-0145FEDER-029697 and UIDB/00100/2020). M. P. Mitoraj

\section{References}

1 R. J. Kuppler, D. J. Timmons, Q.-R. Fang, J.-R. Li, T. A. Makal, M. D. Young, D. Yuan, D. Zhao, W. Zhuang and H.-C. Zhou, Coord. Chem. Rev., 2009, 253, 3042-3066.

2 C. Janiak and J. K. Vieth, New J. Chem., 2010, 34, 2366-2388.

3 N. N. Adarsh and P. Dastidar, Chem. Soc. Rev., 2012, 41, 3039-3060.

4 M. P. Suh, H. J. Park, T. K. Prasad and D. W. Lim, Chem. Rev., 2012, 112, 782-835.

5 H. Wu, Q. Gong, D. H. Olson and J. Li, Chem. Rev., 2012, 112, 836-868.

6 R. J. Kuppler, D. J. Timmons, Q. R. Fang, J. R. Li, T. A. N. Stock and S. Biswas, Chem. Rev., 2012, 112, 933-969.

7 M. Ruben, J. Rojo, F. J. Romero-Salguero, L. H. Uppadine and J.-M. Lehn, Angew. Chem., Int. Ed., 2004, 43, 3644-3662.

8 L. N. Dawe, T. S. M. Abedin and L. K. Thompson, Dalton Trans., 2008, 1661-1675.

9 L. N. Dawe, K. V. Shuvaev and L. K. Thompson, Inorg. Chem., 2009, 48, 3323-3341.

10 L. N. Dawe, K. V. Shuvaev and L. K. Thompson, Chem. Soc.

Rev., 2009, 38, 2334-2359.

11 J. R. Li, J. Sculley and H. C. Zhou, Chem. Rev., 2012, 112, 869-

932.

12 M. Yoon, R. Srirambalaji and K. Kim, Chem. Rev., 2012, 112, 1196-1231.

13 G. Givaja, P. Amo-Ochoa, C. J. Gómez-García and F. Zamora, Chem. Soc. Rev., 2012, 41, 115-147.

14 O. M. Yaghi, H. Li and T. L. Groy, Inorg. Chem., 1997, 36, 4292-4293.

15 B. D. Wagner, G. J. McManus, B. Moulton and M. J.

Zaworotko, Chem. Commun., 2002, 2176-2177.

16 A. M. Beatty, Coord. Chem. Rev., 2003, 246, 131-143.

17 C. L. Chen, B. S. Kang and C. Y. Su, Aust. J. Chem., 2006, 59, 3-18.

18 X. P. Li, J. Y. Zhang, M. Pan, S. R. Zheng, Y. Liu and C. Y. Su, Inorg. Chem., 2007, 46, 4617-4625.

19 F. Frostemark, L. A. Bengtsson and B. Holmberg, J. Chem. Soc., Faraday Trans., 1994, 90, 2531-2539.

20 Y. H. Yeom, Y. Kim and K. Seff, J. Phys. Chem. B, 1997, 101, 5314-5318.

21 Y. H. Yeom, Y. Kim and K. Seff, Microporous Mesoporous Mater., 1999, 28, 103-112.

22 Y. H. Zhao, H. B. Xu, Y. M. Fu, K. Z. Shao, S. Y. Yang, Z. M. Su, X. R. Hao, D. X. Zhu and E. B. Wang, Cryst. Growth Des., 2008, 8, 3566-3576.

23 X. L. Wang, Y. Q. Chen, Q. Gao, H. Y. Lin, G. C. Liu, J. X. Zhang and A. X. Tian, Cryst. Growth Des., 2010, 10, 2174-2184.

24 A. C. Wibowo, S. A. Vaughn, M. D. Smith, M. D and H. C. Loye, Inorg. Chem., 2010, 49, 11001-11008.

25 J. He, M. Zeller and A. D. Hunter and Z. Xu, J. Am. Chem. Soc., 2012, 134, 1553-1559.

26 Y.-X. Tan, F.-Y. Meng, M.-C. Wu and M.-H. Zeng, J. Mol. Struct., 2009, 928, 176-181.

27 A. Bauzá, T. J. Mooibroek and A. Frontera, Chem. Rec., 2016, 16, 473-487. 
28 G. Mahmoudi, A. Bauza, M. Amini, E. Molins, J. T. Mague and A. Frontera, Dalton Trans., 2016, 45, 10708-10716.

29 G. Mahmoudi, D. A. Safin, M. P. Mitoraj, M. Amini, M.

Kubicki, T. Doert, F. Locherere and M. Fleck, Inorg. Chem.

Front., 2017, 4, 171-182.

30 G. Mahmoudi, A. V. Gurbanov, S. R. Hemida, R. Corballo, M.

Amini, A. Bacchi, M. P. Mitoraj, F. Sagan, M. Kukulka and D.

A. Safin, Inorg. Chem., 2017, 56, 9698-9709.

31 G. Mahmoudi, E. Zangrando, M. P. Mitoraj, A. V. Gurbanov,

F. I. Zubkov, M. Moosavifar, I. A. Konyaeva, A. M. Kirillov and

D. A. Safin, New J. Chem., 2018, 42, 4959-4971.

32 A. Bauzá, S. K. Seth and A. Frontera, Coord. Chem. Rev., 2019, 394, 107-125.

33 I. Alkorta, J. Elguero and A. Frontera, Crystals, 2020, 10, 180.

34 F. A. Afkhami, G. Mahmoudi, F. Qu, A. Gupta, E. Zangrando,

A. Frontera and D. A. Safin, Inorg. Chim. Acta, 2020, 502,

119350.

35 S. A. Southern, D. Errulat, J. M. Frost, B. Gabidullin and D. L. Bryce, Faraday Discuss., 2017, 203, 165-186.

36 F. A. Afkhami, A. A. Khandar, G. Mahmoudi, W.

Maniukiewicz, J. Lipkowski, J. M. White, R. Waterman, S. G.

Granda, E. Zangrando, A. Bauzá and A. Frontera,

CrystEngComm, 2016, 18, 4587-4596.

37 G. Mahmoudi, F. A. Afkhami, H. S. Jena, P. Nematollahi, M. D.

Esrafili, P. Garczarek, K. Van Hecke, M. S. Gargari and A. M.

Kirillov, New J. Chem., 2016, 40, 10116-10126.

38 F. A. Afkhami, A. A. Khandar, G. Mahmoudi, W.

Maniukiewicz, A. V. Gurbanov, F. I. Zubkov, O. Şahin, O. Z.

Yesilel and A. Frontera, CrystEngComm, 2017, 19, 1389-

1399.

39 F. A. Afkhami, A. A. Khandar, G. Mahmoudi, M. Amini, E.

Molins, P. Garczarek, J. Lipkowski, J. M. White and A. M.

Kirillov, Inorg. Chim. Acta, 2017, 458, 68-76.

40 G. Mahmoudi, A. A. Khandar, J. White, M. P. Mitoraj, H. S. Jena, P. Van Der Voort, N. Qureshi, A. M. Kirillov, K. Robeyns and D. A. Safin, CrystEngComm, 2017, 19, 3017-3025.

41 G. Mahmoudi, J. K. Zaręba, A. Bauza, M. Kubicki, A. Bartyzel, A. Keramidas, L. Butusov, B. Miroslaw and A. Frontera, CrystEngComm, 2018, 20, 1065-1076.

42 M. P. Mitoraj, A. Michalak and T. Ziegler, J. Chem. Theory Comput., 2009, 5, 962-975.

43 J. P. Wagner and P. R. Schreiner, Angew. Chem. Int. Ed., 2015, 54, 12274-12296.

44 D. Liptrot and P. Power, Nat. Rev. Chem., 2017, 1, 0004. 45 J. Li, G. P. Yang, L. Hou, L. Cui, Y. P. Li, Y. Y. Wang and Q. Z. Shi, Dalton Trans., 2013, 42, 13590-13598.

46 X. A. Luo, X. A. Zhang, Y. L. Duan, X. L. Wang and J. M. Zhao, Dalton Trans., 2017, 46, 6303-6311.

47 A. M. P. Peedikakkal, H. S. Quah, S. Chia, A. S. Jalilov, A. R. Shaikh, H. A. Al-Mohsin, K. Yadava, W. Ji and J. J. Vittal, Inorg. Chem., 2018, 57, 11341-11348.

48 V. A. Blatov, A. P. Shevchenko and D. M. Proserpio, Cryst. Growth Des., 2014, 14, 3576-3586.

49 Y.-J. Shi, Y. Xu, Y. Zhang, B. Huang, D.-R. Zhu, C.-M. Jin, H.-G. Zhu, Z. Yu, X.-T. Chen and X.-Z. You, Chem. Lett., 2001, 30, 678-679.

50 Y.-J. Shi, L.-H. Li, Y.-Z. Li, Y. Xu, X.-T. Chen, Z. Xue and X.-Z. You, Inorg. Chem. Commun., 2002, 5, 1090-1094.

51 G. Mahmoudi, A. Bauzá and A. Frontera, Dalton Trans., 2016, 45, 4965-4969.

52 G. Mahmoudi, A. Bauzá, A. Frontera, P. Garczarek, V.

Stilinović, A. M. Kirillov, A. Kennedy and C. R-Pérez,

CrystEngComm, 2016, 18, 5375-5385. 
53 G. te Velde, F. M. Bickelhaupt, E. J. Baerends, C. Fonseca Guerra, S. J. A. van Gisbergen, J. G. Snijders and T. Ziegler, J. Comput. Chem., 2001, 22, 931-967.

54 A. Michalak, M. Mitoraj and T. Ziegler, J. Phys. Chem. A, 2008, 112, 1933-1939.

55 E. J. Baerends, T. Ziegler, A. J. Atkins, J. Autschbach, O. Baseggio, D. Bashford, A. Bérces, F. M. Bickelhaupt, C. Bo, P. M. Boerrigter, L. Cavallo, C. Daul, D. P. Chong, D. V. Chulhai, L. Deng, R. M. Dickson, J. M. Dieterich, D. E. Ellis, M. van Faassen, L. Fan, T. H. Fischer, A. Förster, C. Fonseca Guerra, M. Franchini, A. Ghysels, A. Giammona, S. J. A. van Gisbergen, A. Goez, A. W. Götz, J. A. Groeneveld, O. V. Gritsenko, M. Grüning, S. Gusarov, F. E. Harris, P. van den Hoek, Z. Hu, C. R. Jacob, H. Jacobsen, L. Jensen, L. Joubert, J. W. Kaminski, G. van Kessel, C. König, F. Kootstra, A.

Kovalenko, M. V. Krykunov, E. van Lenthe, D. A. McCormack, A. Michalak, M. Mitoraj, S. M. Morton, J. Neugebauer, V. P. Nicu, L. Noodleman, V. P. Osinga, S. Patchkovskii, M.

Pavanello, C. A. Peeples, P. H. T. Philipsen, D. Post, C. C. Pye, H. Ramanantoanina, P. Ramos, W. Ravenek, J. I. Rodríguez, P. Ros, R. Rüger, P. R. T. Schipper, D. Schlüns, H. van Schoot, G. Schreckenbach, J. S. Seldenthuis, M. Seth, J. G. Snijders, M. Solà, M. Stener, M. Swart, D. Swerhone, V. Tognetti, G. te Velde, P. Vernooijs, L. Versluis, L. Visscher, O. Visser, F. Wang, T. A. Wesolowski, E. M. van Wezenbeek, G. Wiesenekker, S. K. Wolff, T. K. Woo and A.L. Yakovlev, ADF 2019.3, SCM, Theoretical Chemistry, Vrije Universiteit, Amsterdam, The Netherlands; http://www.scm.com. 56 O. A. Stasyuk, R. Sedlak, C. Fonseca Guerra and P. Hobza, J. Chem. Theory Comput., 2018, 14, 3440-3450.

57 A. Bauzá, T. J. Mooibroek and A. Frontera, Angew. Chem. Int. Ed., 2013, 52, 12317-12321.

58 S. Grabowski, Phys. Chem. Chem. Phys., 2014, 16, $1824-$ 1834.

59 S. Grabowski, Molecules, 2018, 23, 1183-1199.

60 S. Grabowski, Struct. Chem., 2019, 30, 1141-1152.

61 C. Wang, Y. Aman, X. Ji and Y. Mo, Phys. Chem. Chem. Phys., 2019, 21, 11776-11784.

62 I. Cukrowski, F. Sagan and M. P. Mitoraj, J. Comput. Chem. 2016, 37, 2783-2798.

63 F. Sagan and M. P. Mitoraj in Transition Metals in Coordination Environments: Computational Chemistry and Catalysis Viewpoints, Eds.: E. Broclawik, T. Borowski and M. Radoń, Springer International Publishing: Cham, Switzerland, 2019, pp 65-89.

64 M. P. Mitoraj, F. Sagan, D. W. Szczepanik, J. H. de Lange, A. L. Ptaszek, D. M. E. van Niekerk and I. Cukrowski,

ChemPhysChem, 2020, 21, 494-502.

65 K. Müller-Dethlefs and P. Hobza, Chem. Rev., 2000, 100, 143167.

66 S. Grabowski, Chem. Rev., 2011, 111, 2597-2625.

67 M. Teresa Albelda, J. C. Frías, E. García-España and H. J. Schneider, Chem. Soc. Rev., 2012, 41, 3859-3877.

68 H. J. Schneider, Acc. Chem. Res., 2015, 48, 1815-1822.

69 F. Biedermann and H. J. Schneider, Chem. Rev., 2016, 116, 5216-5300.

70 J. Novotný, S. Bazzi, R. Marek and J. Kozelka, Phys. Chem. Chem. Phys., 2016, 18, 19472-19481.

71 P. M. Nowak, F. Sagan and M. P. Mitoraj, J Phys Chem B., 2017, 121, 4554-4561.

72 S. C. C. van der Lubbe and C. Fonseca-Guerra, Chem. Asian J., 2019, 14, 2760-2769.

73 S. P. Thomas, M. S. Pavan and T. N. Guru Row, Chem. 
Commun., 2014, 50, 49-51.

74 D. Sethio, V. Oliveira and E. Kraka, Molecules, 2018, 23, 2763.

75 J. E. Del Bene, I. Alkorta and J. Elguero, J. Phys. Chem. A,

2019, 123, 7270-7281.

76 R. Wysokiński, M. Michalczyk, W. Zierkiewicz and S. Scheiner, Phys. Chem. Chem. Phys., 2019, 21, 10336-10346.

77 M. Michalczyk, W. Zierkiewicz, R. Wysokiński and S. Scheiner, ChemPhysChem, 2019, 20, 959-966.

78 APEX2 and SAINT programs. Bruker AXS Inc., Madison, Wisconsin, USA, 2012.

79 CrysAlis CCD and CrysAlis RED, including ABSPACK Versions

1.171.32.3. Oxford Diffraction Ltd, Abingdon, Oxfordshire,

England, 2006.

$80 \mathrm{~K}$. Harms and S. Wocadlo, XCAD4. University of Marburg, Germany, 1995.

81 G. M. Sheldrick, SHELXS-97, Program for crystal structure solution, University of Göttingen, Germany, 1997.

82 G. M. Sheldrick, Acta Crystallogr., 2008, A64, 112-122. 